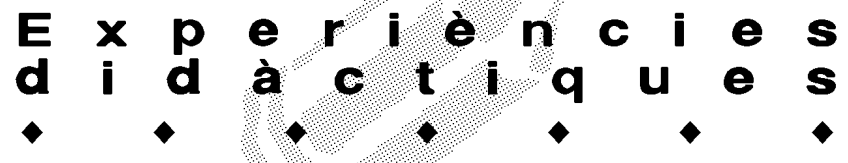

\section{ASSABORINT L'ALIMENTACIÓ: UN REPTE GUSTÓS}

\author{
Amàlia Galdón Delgado i Asunción Juanes García. IES Guadassuar (la Ribera). País Valencià. \\ Enric Ramiro Roca. Àrea de Didàctica de les Ciències Socials. Universitat Jaume I. Castelló.
}

\section{Introducció}

Durant tot el període educatiu de la nostra vida hem tingut moltes assignatures, hem anat a xerrades i hem llegit llibres... en definitiva, hem après moltes coses. Cadascú potser considerarà més important o necessaris alguns aspectes sobre altres, però ben segur que hi haurà consens a definir l'alimentació com un tema d'una gran quotidianeïtat, fonamental per a la salut i no sempre tractat amb la seua corresponent importància. En aquest sentit, el nostre centre va optar per dedicar part del seu esforç educatiu a intentar formar els nostres alumnes. Som conscients que tan sols hem deixat caure un gra de sorra en la immensitat de la necessitat, i que no podem dedicar-hi tot el temps que es mereix, però també que cal iniciar o continuar el procés i clarificar les bases que possibiliten un canvi d'hàbits alimentaris i d'actituds. La societat de consum és la que domina per damunt d'ideologies i fronteres en el món occidental especialment, i per tant sabem que el nostre repte és igual de difícil que de necessari.

Les tasques realitzades han sigut, entre altres, les següents: recollida d'etiquetes i revistes sobre aliments, elaboració i construcció de la piràmide dels aliments, cartells amb lemes, plafons de fotografies, disseny de la baralla Niquita, joc de la margarida misteriosa, joc del penjat, decàleg, logotip de la margarida Niquita i conferències de metges especialistes en la dieta mediterrània. Hem dissenyat l'article de forma breu i sintètica, i en la selecció de fotografies s'il.lustren algunes de les activitats realitzades.

Per ambientar apropiadament els treballs desenvolupats comencem per una descripció de l'entorn de l'institut i de Guadassuar perquè ens coneguem un poc més. A continuació hem resumit algunes de les activitats realitzades i finalitzem amb una perspectiva de futur i alguns materials bàsics que poden orientar l'aproximació al treball sobre l'alimentació. Us assegurem que no és complicat iniciar el camí i que pas a pas el podem fer i gaudir-ne, i convertir-lo en un repte gustós. Finalment agraïm públicament les facilitats i la col-laboració rebudes per la direcció del centre, companys i companyes de l'institut, l'Ajuntament i la participació dels alumnes amb independència que estigueren o no en el projecte i la bona acollida entre els pares i mares de totes les idees que hem aportat per apropar-se a una alimentació més sana.

\section{L'entorn}

Guadassuar és un poble que forma part del País Valencià, banyada pel mar Mediterrani, a l'est d'Espanya, situat a la comarca de la Ribera Alta, de 5525 habitants, de parla valenciana, i que està situat a $39^{\circ} 11^{\prime} 17^{\prime \prime}$ de latitud nord i a $0^{\circ} 28^{\prime} 48^{\prime \prime}$ de longitud oest.

El poble conserva en part una vegetació típicament mediterrània, condicionada pel clima. Es troba a 25 metres sobre el nivell del mar i tan sols la zona de la Garrofera (situada a l'oest del terme) és lleugerament muntanyenca.

La Garrofera és un bosc fruit de la progressiva degradació del bosc autòcton mediterrani, format per carrasques, alzines sureres i pins bords o blancs, amb formacions de garriga-màquia (sajolida, romaní, argelaga, margalló, llentiscle, timó, etc...) on s'intercalen arbres com el garrofer, l'ametller i l'olivera. El terme municipal limita al nord amb els termes de Tous, l'Alcúdia, Carlet i Alginet; a l'est amb el d'Algemesí; a l'oest amb el de Tous i al sud amb els d'Alzira, Massalavés, Montortal i la partida del Ressalany de Benimodo. La seua superfície és de 35,2 km²; la majoria del terme es dedica a la producció agrícola: el conreu de la taronja n'és el principal, però hi ha una zona de bosc i de conreu de l'oliva i de la garrofa.

De clima típicament mediterrani: les temperatures són càlides, caracteritzen uns hiverns suaus ( de $9^{\circ} \mathrm{C}$ a $11^{\circ} \mathrm{C}$ al gener), la mitjana anual és de $17^{\circ} \mathrm{C}$. El tipus climàtic implica una forta secada estiuenca, i es dóna un segon mínim al mes de gener. Les pluges es localitzen a la primavera i a la tardor, es distribuïxen molt irregularment, oscil.len sobre els 450 a $500 \mathrm{l} / \mathrm{m}^{2}$ anuals, que poden caure en pocs dies ("gota freda"); a voltes ocasionen greus perjudicis en els cultius i en el relleu. El poder erosiu de les aigües és fort, modificant severament el paisatge (desforestació, desertització...). La naturalesa del terreny és argilosa i formada pels sediments aportats per les inundacions dels rius Magre i Xúquer (en àrab "El Devastador"). Són materials principalment quaternaris: argiles, arenes i graves.

El terme és creuat en direcció oest a est pel riu 


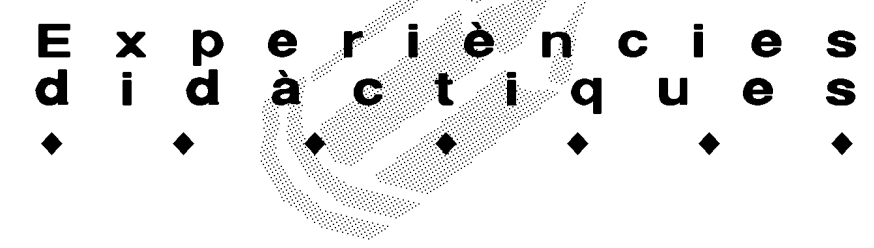

Magre, afluent del Xúquer. Per la part nord és un típic exemple de rambla mediterrània, es caracteritza per la seua prolongada sequera i per les fortes avingudes d'aigua estacionals, com molts dels barrancs que existeixen en la zona muntanyenca. Per la seua importància es pot destacar la sèquia reial del Xúquer, que, des de la seua creació per Jaume I, ha regat aquestes terres $\left(54 \mathrm{~km}^{2}\right)$. Es pot destacar també una antiga obra d'enginyeria, el Cano, un sifó de 155 metres per fer passar les aigües de la sèquia reial per sota del riu Magre. En 1258 ja estava en construcció la sèquia reial i en 1402, pel privilegi del rei Martí l'Humà, arribava al Cano. En 1771 va arribar fins a Sollana i Silla.

Una població bàsicament dedicada a l'agricultura, tendència que s'ha trencat. Ara la majoria de la població es dedica a la indústria i els serveis; l'agricultura ha passat a la tercera ocupació de la població. Al municipi hi ha una escola esportiva municipal, clubs esportius, piscina, camp de futbol, parcs per als xiquets... Hi ha una biblioteca municipal on es poden realitzar consultes per les vesprades. Una Escola de Música de la qual s'alimenta de músics la banda "Unió Musical Santa Cecília de Guadassuar", i dóna oportunitat a la població del poble per a adquirir una cultura musical. La societat musical es divideix en una banda jove (on s'adquireixen els coneixements més elementals) i l'orquestra de cambra (formada bàsicament per instruments de corda), i també hi ha una coral.

\section{L'institut: físic, humà i ambient}

L'institut on treballem es troba ubicat als afores del poble, junt a l'escola de primària, amb molta llum, d'on es divisa l'Alcúdia (població propera a Guadassuar), una gran planura de tarongers i altres arbres fruiters, pous de reg, etc. Aquest edifici és de nova construcció, on ens hem traslladat aquest mateix curs 2004/05. És un edifici de dues plantes, que consta de vuit aules classe (quatre en la planta baixa i quatre en la primera planta), aules específiques de tecnologia, música, informàtica, plàstica i visual, laboratori de biologia i geologia, laboratori de física i química, gimnàs, cafeteria, secretaria, consergeria, despatx del director, despatx del cap d'estudis, seminaris: d'arts i tecnologia, de ciències, d'humanitats i de llengües i un gran pati d'esplai amb un camp de futbet. Totes aquestes instal-lacions, que a l'altre edifici eren deficients o inexistents, com el gimnàs i seminaris, afavoreixen en gran manera la tasca de l'educació.

El claustre el formem vint professors/es i un rector a temps parcial, a més a més, l'administratiu, la conserge i el personal de la neteja. Som un grup reduït de persones treballant i açò fa que estigam prou units formant una gran família, en la que quasi tots estem participant en algun projecte (reciclatge de paper, pla d'evacuació de l'institut, Comenius, Jove consumidor, Trobades d'ensenyament en valencià, Portfolio, etc.)

\section{Piràmide dels aliments}

Amb l'objectiu comú de confeccionar una gran piràmide alimentària, en aquesta activitat els alumnes han posat en funcionament un conjunt de tècniques i procediments de diverses assignatures.

Cadascun dels alumnes ha portat fotografies dels diversos aliments que han aconseguit visitant els comerços de la localitat, per la qual cosa han estat implicats els botiguers. Com que, per les seues característiques, a Guadassuar no hi ha grans superfícies, han hagut de fer una recerca en profunditat per aconseguir pòsters i propagandes, o bé han hagut de convèncer els seus familiars i/o aprofitar els viatges a altres ciutats per poder localitzar fullets de propaganda.

La confecció del plafó s'ha dividit en grups d'alumnes: uns han dissenyat, mesurat i retallat els diferents ele-

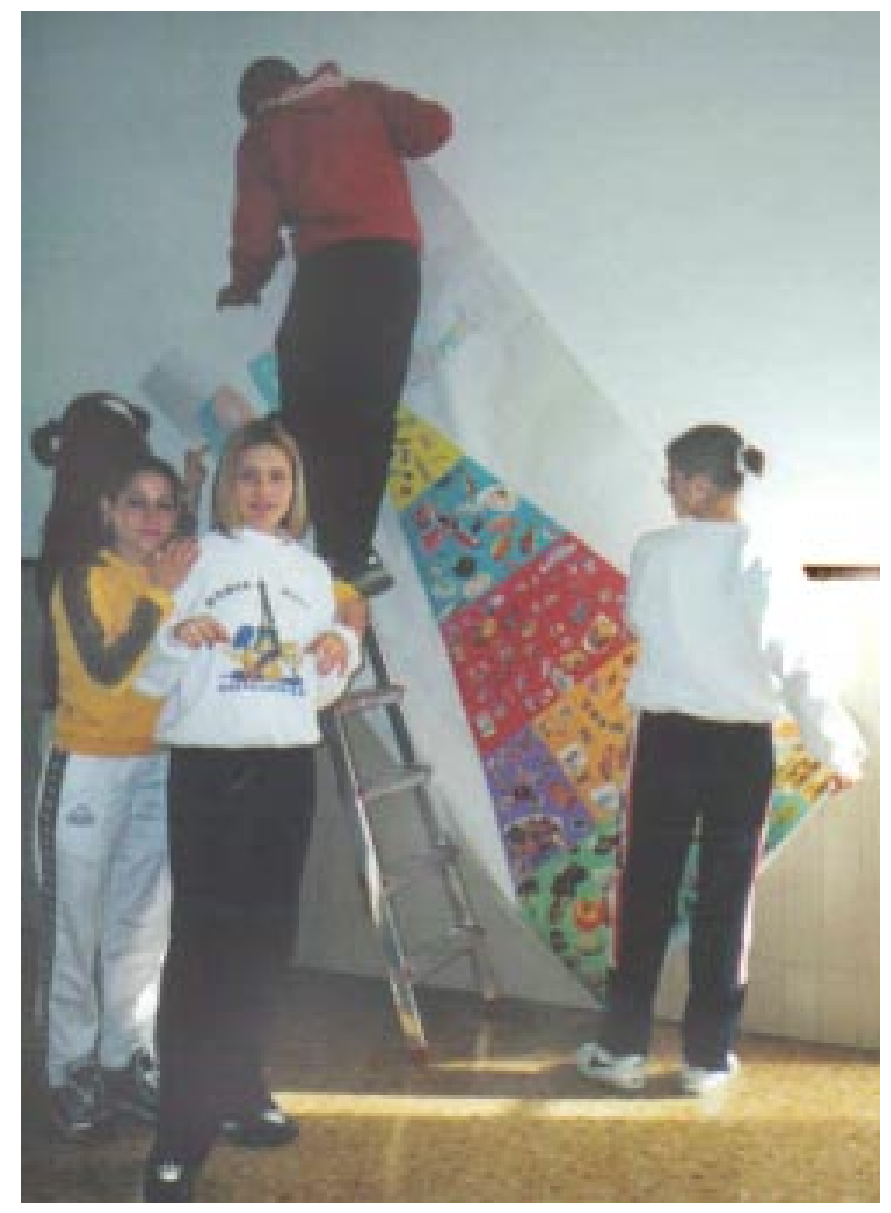

Instal·lació del plafó amb la piràmide dels aliments. 


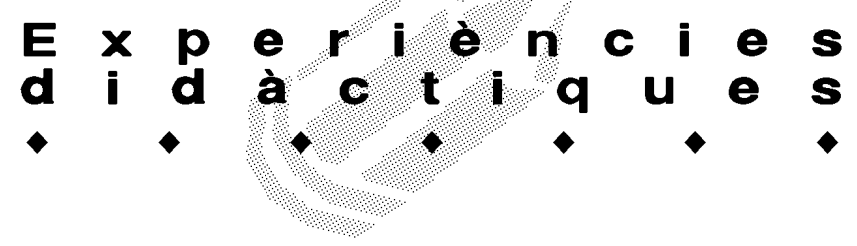

ments necessaris per confeccionar aquesta piràmide gegant, al mateix temps que altres feien un esborrany $i$ elegien el color de les cartolines que consideraven més adequades per a cada grup d'aliments. Finalment, han classificat els aliments per categories i han enganxat sobre el mural les diferents aportacions de les etiquetes que han recollit.

\section{Cartells amb lemes}

L'activitat en una primera fase ha consistit a pensar en una maqueta d'eslògan que es poguera generalitzar. Després de nombroses intervencions defensant la seua proposta, s'ha passat a la votació de la frase preferida, que ha estat:

JA SAPS - frase a inventar - MENJA SA.

Per exemple: JA SAPS, ALIMENTA'T BÉ I MENJA SA.

A continuació, a l'aula d'informàtica als grups se'ls han donat les mínimes orientacions d'informàtica per poder confeccionar aquests versos, ja que més de la meitat no tenien les mínimes destreses per poder-ho fer. Després d'aquest curset accelerat de Word: tipus de lletra, vores del marge, ubicació dels versos... s'han confeccionat els diferents cartells amb el denominador comú de fer referència a una bona alimentació. Després els alumnes per parelles han repartit els fulls pels passadissos de tot l'institut.

\section{Conferència sobre la dieta mediterrània}

Hem comptat amb la col-laboració dels metges Josep Ferris, pediatre a València i Algemesí, i Julia García a Port de Sagunt, ambdós especialistes en dieta mediterrània, i també autors d'articles i llibres sobre aquest tema. Varen impartir una sèrie de xerrades als grups de primer i segon d'ESO de l'institut, celebrades a l'auditori de la localitat.

Els alumnes, dels apunts que prengueren sobre el tema, confeccionaren diferents redaccions referides a les característiques de la dieta mediterrània i la seua importància, dins l'assignatura de Ciències Naturals. A partir d'aquesta iniciativa, està prevista una campanya per millorar l'alimentació entre tota la comunitat educativa, i fer especial insistència en els pares i mares d'alumnes. Ja s'ha parlat amb la junta de l'AMPA, que s'ha mostrat molt interessada, ha donat el seu vist-i-plau i s'ha implicat en el tema. No obstant això, aquestes activitats fins al moment present no s'han desenvolupat.

\section{Plafó amb fotografies}

El grup de fotografia, ubicat al si de l'optativa "Redacció i disseny de premsa”, s'encarregava d'arreplegar algunes instantànies visuals del treball que es feia en totes les activitats realitzades; després es duien a revelar, s'escollien les més interessants i s'exposaven en un plafó pel passadís de l'institut. Algunes d'aquestes fotografies han servit per il-lustrar aquest article, com per exemple la que mostra el plafó amb la piràmide dels aliments.

\section{Treball curricular}

Les assignatures que han portat endavant l'activitat són:

Tecnologia: S'han dissenyat jocs de respostes múltiples, confeccionats amb llautó i circuits elèctrics per relacionar la resposta correcta amb un llum encès o un xiulet. Aquesta activitat ha suposat molt més treball del previst en un principi, i no s'ha portat encara a la pràctica.

Llengües: Des de les diferents assignatures d'aquest seminari de professorat, s'ha impulsat el treball relacionat amb els aliments i la confecció de frases curtes que sintetitzaren missatges positius relacionats amb la dieta mediterrània i els hàbits sans, i alguns missatges del que no s'ha de fer si es vol tindre una alimentació

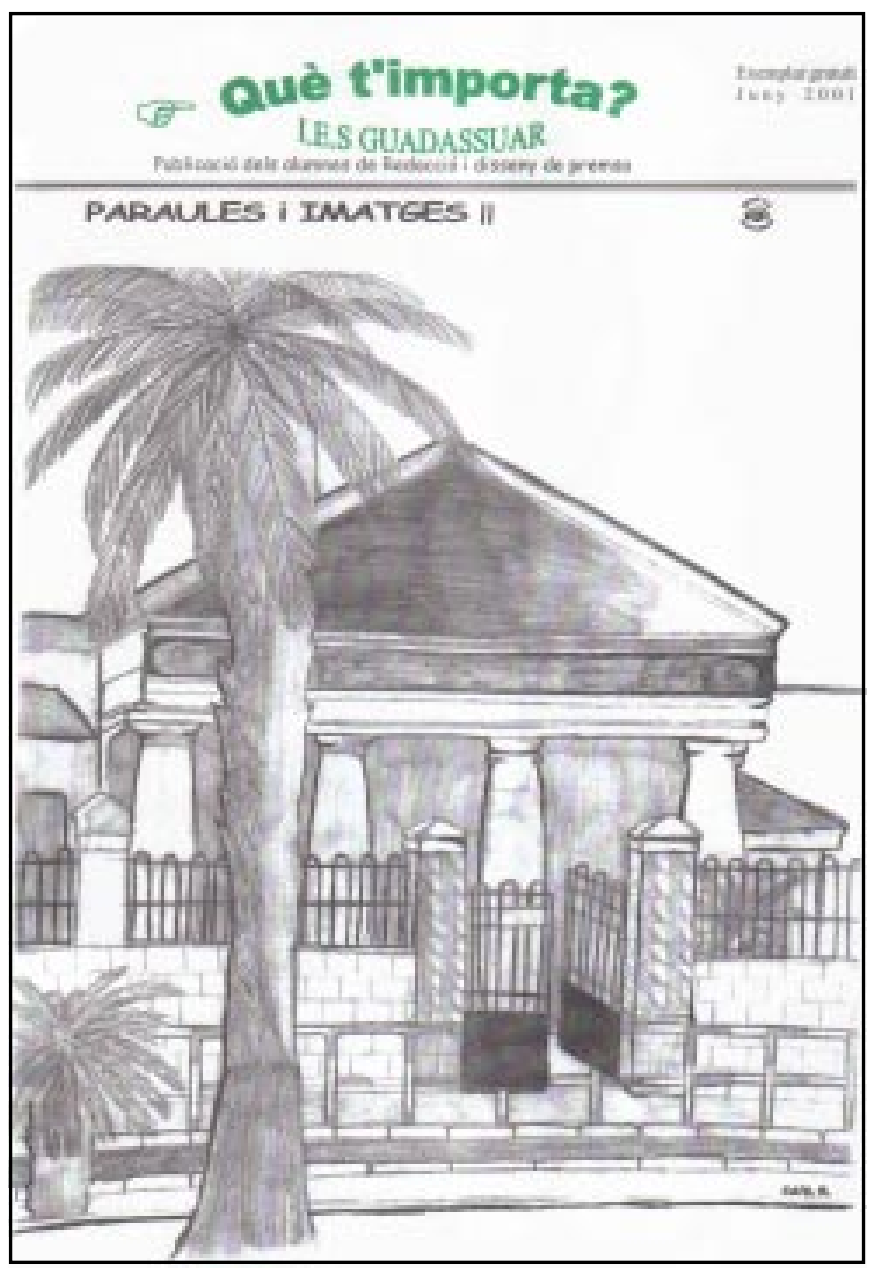




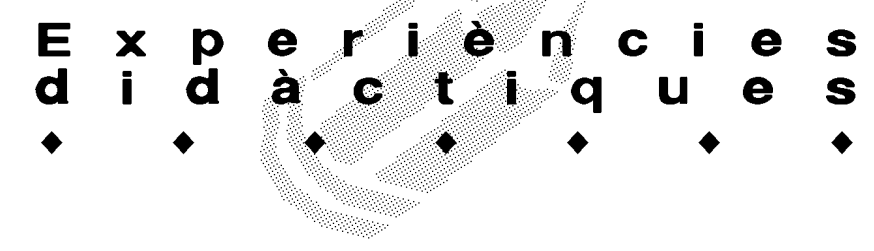

apropiada.

Medi Ambient: Ha estat la matèria central del projecte. Des d'ací s'han dirigit i coordinat els esforços per aconseguir l'èxit del projecte. Igualment els alumnes de l'optativa han estat els iniciadors i animadors de gran part de les activitats.

Redacció i disseny de Premsa: Aquesta altra asignatura s'ha encarregat tant de la publicitat del projecte a tota la comunitat escolar com de la realització de les fotografies en totes les activitats realitzades.

\section{Perspectiva de futur}

Com a conseqüència d'aquesta primera experiència i dels bons resultats obtinguts, s'ha previst dedicar el proper curs a la confecció d'un treball interdisciplinari on participe tot l'institut, centrant les Jornades de febrer en el tema de l'alimentació. Fruit d'aquest treball ha estat l'acord del claustre per instal-lar una màquina de sucs de taronja en el pati del centre i el compromís per part del professorat per impulsar el seu ús.

Sobre el contingut s'han realitzat les següents tasques:

- Recollida de fotografies de diferents aliments per confeccionar la piràmide alimentària (mural).

- Recollida d'etiquetes de diferents productes i marques, per comparar composicions, preus i realització de jocs (baralles de cartes, el penjat i la margarida misteriosa...). També s'han fet eslògans i el decàleg.

- Conferències.

El motiu principal que ens ha mogut a realitzar aquest projecte ha estat que veiem que segons avançàvem en tecnologia perdíem els nostres hàbits alimentaris, per la qual cosa ens va preocupar la alimentació dels alumnes.

El treball s'ha iniciat perquè es participava en el concurs del Jove Consumidor Europeu, "alimentació equilibrada".

La informació l' hem recollida a través de metges, llibres, pàgines web, observació i estudi d'etiquetes.

La utilitat és proporcionar a l'alumnat l'oportunitat de menjar sa.

\section{Bibliografia sobre educació per al consum}

BALLESTRA, G. i altres. Comerç, indústria, alimentació. Proposta de recerca a l'escola. Quaderns de recerca GUIX. Barcelona. 1980.

BALZOLA, A. La infantita quiere buñuelos. Edit. SM. Madrid. 2003. (Un llibre original).

BAREDES, C. i LOTERSZTAIN, L. ¿ Por qué es trompudo el elefante? Y otras curiosidades de los animales a la hora de comer. Ed. Lamiqué. Buenos Aires. 2003. (Un llibre divertit, didàctic i per a aprendre).

BENGOECHEA, J. G. y VARA GARcíA, M. T. Cuenta con tu planeta. Ed. Animación y promoción del medio. Madrid. 1993. (Un joc gratuït, patrocinat per Tetra Pak).

CD Cómete el mundo. Caja Madrid. Obra Social (gratuït).

CAM. Agenda del Medi Ambient. Ed. CAM Joven i Universitat Politècnica de València. 2005. (Una agenda gratuïta).

CONSELLERIA DE SANITAT I CONSUM. Viure en Salut. València. 2005. (Una revista institucional gratuïta).

CRA el Trescaire-Benlloch, la Pobla, Vilanova, la Torre. La dolça gastronomia. Ed. Fundació Enric Soler i Godes. Castelló. 2002. (Un llibre gustós).

GENERALITAT DE CATALUNYA. El consum a l'escola. Ed. Departament d'Ensenyament. Barcelona. 1987. (Un Ilibre institucional).

INSTITUTO NACIONAL DE CONSUMO. La educación del consumidor en la escuela. Madrid. 1984. (Fabulós i pràctic, si el podeu aconseguir).

JENNINGS, T. Els aliments. Ed. Cruïlla. Barcelona. 1989.

ORTIFUS. Consejos prácticos para ir por la vida con sumo cuidado. Ed. Conselleria de Sanitat i Consum. València. 1990. (Acudits-vinyeta sobre el consum).

RAMON, D. Els gens que mengem. Ed. Bromera. Alzira. 1997. 2000.

SAPIÑA, F. Un futur sostenible? Ed. Bromera. Alzira.

SUST, X. Menjar gratis. Ed. Ara Llibres. Barcelona. 2002. (Un llibre ben aprofitat).

TARRES, A. Amb el consum, no val a badar. Ed. Institut Català de Consum. Barcelona. 1994.

\section{Pàgines web}

Generalitat valenciana:

http://intercentres.cult.gva.es/cefire/46401581/biblioteca/ Cat\%C3\%A0leg\%20Educaci\%20per\%20al\%20consum_1.html

Generalitat de Catalunya:

http://www.xtec.es/recursos/valors/consum.htm

Col.legi de Farmacèutics (dinar a l'escola):

http://www.farmaceuticonline.com/escoles/escola_ dinar.html

Institut Català de Consum (per a professors):

http://www.icconsum.org

Fundació Autònoma Solidària (aliments que ajuden a superar amb èxit el període d'exàmens):

http://magno.uab.es/fas/fas/alimentacio_portada.htm

Pàgina personal de Miquel Angel Mulet (Dieta equilibradal Requeriments nutritius/Snack/La composició dels aliments/ Receptari):

http://www.xtec.es/ mmulet/trofos/index1.htm 